\title{
Understanding the Effects of Siblings \\ on Child Mortality: Evidence from India
}

\author{
Gerald Makepeace \\ Cardiff Business School \\ Colum Drive Cardiff CF10 3EU, UK \\ E-mail: makepeace@cardiff.ac.uk \\ Fax: $44-(0) 29-20874419$ \\ and \\ Sarmistha Pal* \\ Department of Economics and Finance \\ Brunel University, Uxbridge UB8 3PH, UK \\ E-mail: sarmistha.pal@brunel.ac.uk \\ Fax: 44-(0)1895-269770
}

October 2006

\begin{abstract}
Given the intrinsically sequential nature of child birth, timing of a child's birth has consequences not only for itself, but also for the older and younger siblings. The paper thus argues that prior and posterior spacing between consecutive siblings are important measures of the intensity of competition among siblings for limited parental resources. While the available estimates of child mortality tend to ignore this simultaneity bias, we use a correlated recursive model of prior and posterior spacing and child mortality to correct it. There is evidence that uncorrected estimates underestimate the effects of prior and posterior spacing on child mortality.
\end{abstract}

\section{JEL Classification : D13, I12, 015}

Key Words: Sibling rivalry in sequential framework, Prior and posterior birth spacing, Endogeneity bias.

\footnotetext{
* Corresponding author. Sarmistha Pal wishes to thank Cardiff Business School for providing a grant for research assistance. We are most grateful to the Editor Junsen Zhang and three anonymous referees of this Journal for their helpful and insightful comments. We would also like to thank Stephen Jenkins and Stan Panis for helpful suggestions on an earlier version of the paper. The usual disclaimer applies.
} 


\section{Understanding the Effects of Sibling on Child Mortality: Evidence from India}

\section{INTRODUCTION}

Children in low-income countries face much higher risks of mortality compared to their counterparts in more affluent societies. While the infant mortality rate in 1992 was 79 per thousand in India, it was only 26 in Thailand and 13 in South Korea. This disadvantage often arises from the lack of parental resources in societies characterised by credit market imperfections. The problem is further aggravated for larger families with more children as these families need to allocate limited available resources across more consumers. Even in the absence of any strategic behaviour by family members, children compete for limited parental care and resources - a notion commonly labelled as 'sibling rivalry' in economics (Garg and Morduch, 1998). Sibling rivalry implies that sibling composition determines child survival leading Garg and Morduch (1998) to include number of brothers and sisters or number of older brothers and sisters in a child health function. These indicators of sibling rivalry cannot however capture the intensity of competition between prior and posterior siblings. By the time a child is born, an older sibling may not require extensive care from the parents and may even help parents by looking after younger siblings or supplementing family earnings. Thus the spacing between consecutive children, i.e., the age composition of siblings could capture the intensity of competition between successive siblings better though this measure has not been adequately taken account of in the existing literature.

There has been a long tradition of investigating the relationship between fertility and mortality in low income countries. While most researchers observe strong negative effects of fertility on child mortality (e.g., see Benefo and Schultz, 1996), LeGrand and Phillips (1996) report that the expected effect of higher total fertility on mortality reduction in rural Bangladesh has not been very strong. ' Others have considered the effects of birth interval on child mortality. For example, Curtis, Diamond and McDonald (1993) report that shorter birth interval significantly increases post-neonatal mortality in Brazil. Choe, Diamond, Kim and Steele (1998) further compare the effects of son preference on child mortality in Bangladesh, Egypt and South Korea and find indirect evidence that shorter birth spacing leads to higher mortality. 
There is a large literature in demography that suggests that longer birth spacing (and therefore lower fertility) is associated with lower child mortality. The explanations for this inverse relationship include, among others, less maternal depletion and more resources and parental care per child. While spacing decisions are clearly made in conjunction with other decisions about the allocation of resources pertinent to the health of existing children, most existing studies treat spacing to be exogenously given within a static one-period framework. Ronsezweig (1986) has highlighted the intrinsically sequential nature of decisions regarding child birth. A sequential framework emphasises the simultaneity between spacing and mortality variables: the timing of a child's birth has consequences not only for his or her self, but also for his/her older and younger siblings. This is because there is a jointness of spacing decisions within a sequential framework: an increase in parental age at the birth of a particular child affects its older sibling's post-birth interval and its younger siblings' prior birth interval. In this context, the present paper examines the effects of both prior and posterior birth spacing (that measures age composition) and gender of the first child (that measures gender composition) on child mortality.

Given that birth spacing reflects age differences between consecutive siblings, use of a sequential framework also enables us to capture the intensity of competition among siblings (depending on their age-related needs) better than a standard static framework. For example, if the spacing is short, an older sibling may not be independent when the younger sibling is born and both children would require the close attention of their parents, which in turn may cause a strain on parental resources, adversely affecting health of both the current and the older child. In contrast, if the spacing is sufficiently long, the adverse effect of a new birth will be less as the older sibling would need less attention from the parents and the parents can devote more of their time and energy towards the younger sibling. The relationship may be more complex. For example, longer birth spacing beyond a certain limit may give rise to some kind of intra-family conflicts including diverse child investments that do not require complementarities and maternal depletion at the other end. Some psychological literature suggests that older child may resent the attention paid to the younger sibling if the intervals are long as the older child has had more time alone with the parents. The relationship may thus be non-linear so that longer spacing may be beneficial up to a certain extent but beyond that the relationship may be reversed.

The issue of sibling rivalry is closely related to available family resources. The Beckerian model (1991) explains the nature of parental investment in children and the quantity-quality trade-off within a static framework when there are imperfections in labour and credit markets. In the presence of these constraints, children will do better when 
accompanied by siblings with fewer intrinsic advantages. Introduction of gender may generate further complexity in the intra-household allocation decisions. Thus for a society with a pro-male bias (Behrman et al., 1982; Sen and Sengupta, 1983), younger children with more older sisters will be better off than those with more older brothers. This aspect of gender is incorporated in our sequential analysis where gender of the current as well as that of the first child is used as a possible measure of gender composition of siblings.

Our analysis uses complete birth history data obtained from the 1992-93 National Family Health Survey (NFHS) from the eastern Indian state of West Bengal. We consider the birth history of women aged 13 to 49 years ${ }^{\text {ii }}$ belonging to households often characterised by resource constraint and son preference (Pal, 1999). Our central result is that child mortality decreases with increases in either prior or posterior spacing (although the size of the fall is different). Demonstrating this simple proposition raises a number of estimation problems that we address here.

We use a correlated recursive system to estimate child mortality jointly with prior and posterior spacing decisions, allowing for mother/family specific unobserved heterogeneity in each equation in the model. We also allow for non-zero pair-wise correlations between the unobserved factors determining birth spacing (prior/posterior) and child mortality; the latter is possible because the same couple makes these decisions. For example, at the same level of education and wealth and other observables, parents who choose to have shorter birth spacing intervals may also have higher death rates for their child because of this common unobserved parental effect. In this case, low values for birth spacing would be associated with high unobserved values for the propensity to die creating a correlation between birth spacing and the unobservable error term in the mortality equation. By modelling this aspect of the data generation as a common fixed effect (note that the fixed effect has different impacts on birth spacing and mortality), we are able to remove the implicit bias resulting from the correlation. We also propose a recursive structure for our model, ensuring identification in the presence of the common fixed factor (See Chamberlain and Griliches, 1975). Each model (comprising of 3 correlated equations pertaining to posterior and prior spacing and also child mortality) is estimated separately for male and female children in order to reduce biases due to resource allocation in favour of males.

Although our work is similar to that of Rosenzweig (1986), we study the relationship between different fundamental variables. Rosenzweig's measure of child health is gestation period while our index is either whether a child has died or the time to death in the first five years of a child's life. Mortality appears to be of more direct policy relevance in the context of a developing country like India. Birth spacing in Rosenzweig's empirical analysis is 
captured by a binary variable indicating whether the spacing is long or short. We however include both prior and posterior spacing explicitly. This follows Rosenzweig's theoretical specification closely and our results show the importance of prior and posterior spacing on child health; there is also indication that the indirect effects of mother's literacy and household assets on prior and posterior spacing and therefore on child health are asymmetric.

We compare our correlated system estimates with alternative estimates including fixed effects logit estimates of child mortality, corresponding to Rosenzweig's fixed effect estimates. ${ }^{\text {iii }}$ The results obtained from the correlated recursive system are qualitatively similar to the fixed effects estimates produced by Rosenzweig. While our methods complement those of Rosenzweig, these alternative estimates directly support his contention that both prior and posterior spacing are important determinants of child mortality.

We model the endogeneity of birth spacing in a mortality equation by interdependent family fixed effects but we do not specifically address some issues related to child-specific unobservables. There may remain some inputs in the health production function that depend on child-specific endowments. If these inputs depend on factors observed by the family but are not recorded in the data, the error in the mortality equation may have a child specific component that depends on the chance of death. In some cases, the mortality or potential mortality of a particular child may be observed by the family prior to the conception of the next child but the variables affecting this decision are not directly observable in our data during the relevant prenatal period. Nonetheless our approach does address the important endogeneity issue (that arises from the inclusion of spacing as an explanatory variable in the mortality equation), using a technique that has been used successfully elsewhere (e.g., Brien and Lillard, 1994; Lillard and Willis, 1994; Panis and Lillard, 1994).

The paper now considers the hypothesis in greater detail and describes the data and the statistical model (see section 2). Section 3 presents and analyses the results. The findings of the paper are summarised in the final section.

\section{HYPOTHESES, DATA AND METHODOLOGY}

Families maximise the total income of the parents and potential children. The income of each child depends on their health which depends inter alia on the number of other children in the family. There are clear incentives to raise future income by having more children (which means shorter birth spacing) but the earning power of children depends on their quality, measured here by their health. The family's resources are constrained so an increase in the number of children will reduce the health of the children and their future 
earning capacities. This trade-off between quantity and quality (measured here by health) is central to the Beckerian models, which are essentially static. Child birth and effects of siblings on child health are however sequential in nature and hence the rationale for our work is derived from Rosenzweig (1986), ${ }^{\text {iv }}$ who extended the Beckerian models to a sequential framework.

\subsection{Health Production Function}

Rosenzweig (1986) applied the Beckerian framework to a three-period model to determine how birth spacing may affect birth outcomes. A key feature of this model is the health production function, which plays the same role as the child quality production function in the Becker's model.

Assume that the quality $H_{i j}$ (e.g. health) of a child $i$ born to family $j$ depends on its birth order $i$, the age of its mother when born $S_{i}$, the intervals between its birth and both prior and subsequent births and child specific resources $Z_{i j}$. For a child of order $i$ in family $j$ (among $n$ children) who is neither the first nor the last child (in linear form) we have:

$$
H_{i, j}=\gamma_{a} S_{i, j}+\gamma_{p}\left(S_{i, j}-S_{i-1, j}\right)+\gamma_{n}\left(S_{i+1, j}-S_{i, j}\right)+\gamma_{h} Z_{i j}+\delta_{j}+\varepsilon_{i j} \quad 1 .
$$

where $\gamma_{a}$ measures the impact of parental age, $\gamma_{p}$ prior spacing and $\gamma_{n}$ posterior spacing. ${ }^{\mathrm{v}} \delta_{j}$ is an unobserved quality component common to all members of family $j$ and $\varepsilon_{i j}$ is a child specific random error. For the first child $(i=1), \gamma_{p}=0$ while for the last child $\gamma_{n}=0$.

Equation (1), describing the health production technology, displays a jointness of spacing decisions - an increase in the parental age at birth of child $i$ affects its older sibling's post-birth interval and its younger sibling's prior birth interval. This interdependence implies that, even in the absence of differences in child specific endowments $\left(\varepsilon_{i j}=0\right)$, it is unlikely that parents could simultaneously equalize child specific resources $Z_{i j}$ across children and equalise quality outcomes because of the sequential nature of childbearing. Thus child specific investments in health will be correlated with birth order and spacing as well as children's endowments.

In the context of competition among siblings for limited resources, we argue that age differences between consecutive siblings capture an important aspect of the intensity of competition among siblings that is little discussed in the literature. ${ }^{\mathrm{vi}}$ Multiple births (twins/triplets) too will naturally impose a strain on parental resources and may thus increase the competition between the current siblings as well as that between current and existing siblings.

The effects of siblings on child mortality would be further complicated if parents are 
not only resource constrained, but are also characterised by preferences for sons either because of the higher expected earnings of boys (Rosenzweig and Schultz, 1982) or prejudice. We estimate the model separately for male and female children to allow for the possibility that the treatment of a child may depend on its gender. Some researchers (such as Garg and Morduch, 1998 and Butcher and Case (1994)) have used, respectively, the number of female children and 'any daughters' to test for favourable treatment of males. We allow for this possibility within our gender-specific estimating equations by including the gender of the first born as an instrument for number of girls. ${ }^{\text {vii }}$

\subsection{Data}

India is an interesting case to consider because child mortality rates for girls are among the highest in the world. viii There is also an interesting regional variation within the country. Female mortality rate in the 0 to 4 years age group in 1991 was lower than the male mortality rate in the southern states of Andhra Pradesh, Kerala and Tamil Nadu, but higher in most other major states. Our sample is drawn from the eastern Indian state of West Bengal. In the post-independence period, West Bengal started its economic development in a relatively good position among the Indian states as reflected in its high rate of urbanisation, strong industrial infrastructure and very high productivity of land. However, by 1967-68 the incidence of rural poverty was above-average in the state and the situation did not improve perceptibly in the 1980s. For example, though the infant mortality rate (IMR) ${ }^{\mathrm{ix}}$ in rural West Bengal declined between 1981 and 1990, the state's own rate of decline in the 80s was not much faster than the Indian average; in fact, it was surpassed or equalled by Bihar, Uttar Pradesh, Gujarat, Punjab, Kerala and Tamil Nadu (Sengupta and Gazdar, 1997). Table 1A compares West Bengal's demographic performance with important Indian states in 1991.

We use the National Family Health Survey (NFHS) $1992-93^{x}$ household-level data from rural and urban West Bengal. This allows us to construct a complete birth history for each woman aged 13-49 years. Given that in our sample the death rate tails off from age five onwards, age is right censored at 60 months. There are 12,902 children in our sample of whom $51 \%$ are male. Considering the residential location, $81 \%$ male and $82 \%$ of the female children in our sample came from rural areas of the state. About $14 \%$ of both rural male and female children died before reaching the age of 60 months while the corresponding proportion was lower for children living in urban location (10\% for female and $11 \%$ for male). Appendix 1 provides definitions and summary statistics for the variables used. 
A preliminary analysis of the data (shown in Table 2) suggests that the mortality rate for children during their first 5 years is about $13 \%$ across the whole sample. It rises slightly when there is more than one child and birth spacing is less than 12 months but more than doubles when we consider non-first born children with birth intervals of a year or less. The mortality rates are even higher when the child is one of the twins or if the first child is a female. Gender differences are also observed in these estimates, though the extent is rather limited except when the first born is female. If the first born is a female and the birth spacing is a year or under, then subsequent females are over $30 \%$ more likely to die in the first 5 years. It however follows that mortality rates decline if the spacing between consecutive births is between 24-60 months though beyond 84 months the mortality rate may go up somewhat for the non-firstborn children in our sample.

\subsection{Methodology}

The unit of observation is a woman together with the birth history of all her children. The primary hypothesis is that child mortality depends on both prior and posterior birth spacing. Since we do not observe prior birth spacing for first born children and posterior birth

spacing for youngest children, we concentrate on middle order children. ${ }^{x i}$ We model child mortality as a probit equation showing the probability of a child dying in the first 5 years of life. In an alternative specification, we also estimate the corresponding mortality hazard equation (see Appendix 2).

The household chooses the number and age composition (reflecting birth interval) of its children to maximise the present value of income produced by all family members. This income stream depends on the survival prospects of the children. The optimal values of different child variables, such as the number of children and birth spacing, will therefore depend in part on the values of the error term in the mortality equation. If this error term incorporates factors that are constant over children for the family but unobserved in the data, the values of any birth spacing variables in the mortality equation may be correlated with the error. We have attempted to resolve the resulting problems elsewhere (Makepeace and Pal, 2006) using instrumental variables. but the use of weakly correlated instruments may actually exacerbate the problem. Here, we model the source of the endogeneity as a fixed effect reflecting unobserved family-specific heterogeneity that affects both mortality and birth spacing. We then introduce hazard equations to explain birth spacing. Assuming that the fixed effects in the birth spacing and mortality equations are correlated, we estimate the mortality equation purged of the correlation between its error and the birth spacing variables. 
An analogue to this procedure is the treatment model using Heckman-type selection adjustments to correct the error for omitted variable bias. To pursue this analogy, the mortality equation models the outcome of the treatments (birth spacing) and the birth spacing equations the selection into the treatment.

The model is identified by its recursive structure and the covariance restrictions imposed by the inclusion of a fixed effect in each equation. This issue is discussed in Chamberlain and Griliches (1975). ${ }^{\mathrm{xii}}$ The non-linear form of the model also guarantees identification.

\section{Child mortality equation}

The mortality equation shows the probability that a child dies within 5 years of birth. For the $i$-th child born to $j$-th mother, the propensity to die is given by:

$$
D_{i j} *=\beta_{1} Z_{M j}+\beta_{2} X_{M i j}+\beta_{3} P R E V_{i j}+\beta_{4} N E X T_{\mathrm{ij}}+\delta_{j}+u_{M i j}
$$

The child dies if $D_{i j} *>0$ and death is recorded by the dummy variable, $D_{j}$, that takes the value 1 if the child has died. PREV and NEXT are the prior and posterior 'birth spacing' variables showing the lengths of time between the birth of the current child and the births, respectively, of the previous child and the next child. $X_{M}$ and $Z_{M}$ are respectively vectors of exogenous child-specific and household-specific covariates. We adopt a probit specification that enables

family-specific differences, $\delta_{j}$, to be modelled as random effects. $u_{M i j}$ is a child-specific random error independently and identically distributed with zero mean and unit variance. . $^{\text {iii }}$

PREV and NEXT reflect the potential effect that sibling competition has on child health outcomes since rivalry may decline as the age gap increases. Thus parents can devote more time and effort to rearing a child if either prior or posterior birth spacing is longer.

In general, the probability that the $i$-th child dies will depend on a vector of other characteristics. Among the individual child specific characteristics, we include if the current child is a twin. Multiple birth (twins/triplets) may impose a strain on parental resources and may thus increase the competition among the current siblings as well as that between current and existing siblings. To this effect, we include a binary variable to indicate if the current child is one of twins. $x i v$

If parents are characterised by son preference, the gender of the current child could be important determinant of child mortality. In order to reduce the effects of pro-male bias in the pooled sample, we separately estimate the mortality functions for boys and girls in our 
sample; this allows us to examine how the same set of individual/household characteristics may affect survival of male and female children differently.

All the remaining covariates are household-specific. Preferences for sons in Indian society are found to be important in birth spacing and therefore in child survival. As explained earlier, we examine whether gender of the first child has a direct/indirect (via its effect on spacing) impact on mortality. In addition, we include a number of variables reflecting various aspects of health. The dummy for 'whether the first child died' may take account of 'death clustering' such that families experiencing child death may have shorter birth intervals (Dasgupta, 1997) and higher mortality rates.

The provision of public services like safe drinking water, sanitation or use of other health inputs (like immunisation) will also affect child health. ${ }^{\mathrm{xv}}$ We did include both access to modern toilet and safe drinking water in the mortality equation, but none of them turn out to be significant. As an alternative, we tried including a binary variable for rural residential location because provision of public services tends to be worse in rural areas of the state. This rural dummy would account for the effects of inter-regional (rural/urban) variation in public services on child mortality within the state. Note however that residential location (rural/urban) is the location at the time of the survey and may not reflect location during the first five years of a child's birth especially if the family moves over time.

Our model emphasised the role of family resources. Since literate mothers tend to be more educated ${ }^{\mathrm{Xvi}}$ and from higher income families, we use mother's literacy as a proxy for income and wealth. Since NFHS data do not provide any information on household income or expenditure, we also include some key household assets variables, namely, ownership of land and brick-built houses, to control for variation in wealth effects. Religion may also be considered to be an important determinant of socio-cultural practices, e.g., defining pro-male bias, which in turn could affect parental allocation for investment in children. To this end, we include a dummy for Muslim children. ${ }^{\text {xvii }}$

In an alternative specification, a proportional hazard model of mortality is estimated (see Appendix 2). In addition to the above mentioned variables, in this case we include three more variables to capture the baseline hazard. In particular, we define two nodes, namely, 3 and 6 months and using these two nodes we create three additional variables: if the child dies in the intervals: under 3 months, 3-6 months and above 6 months. Each new variable represents the original spacing variable on a specific segment of its range so that the estimated effect of the splines is no longer linear, but piece-wise linear. These spline coefficients may directly be interpreted as slope coefficients (Panis, 1994). 


\section{Birth spacing equations}

Posterior spacing: The log hazard rate of spacing from the time of birth of child $i$ (born to the $j$ th woman) till the arrival of the next sibling (NEXT) is a function of calendar time $(T(t))$ and household $\left(Z_{2 j}\right)$ and individual child-specific $\left(X_{2 j j}\right)$ characteristics and a family-specific ${ }^{\text {xviii }}$ heterogeneity component $\varepsilon_{j}$ common to all children in the $\mathrm{j}$-th family. It is:

$$
\operatorname{Ln} h_{i j}^{N E X T}\left(t, \mathcal{E}_{j}\right)=\alpha_{0}+\alpha_{1} Z_{N j}(t)+\alpha_{2} X_{N i j}(t)+\alpha_{3} T(t)+\varepsilon_{j}+u_{N i j}
$$

This model is proportional in the sense that the hazard is characterised in terms of a baseline hazard that captures duration dependency and proportional shifts of the baseline hazard..

Prior birth spacing: In a similar fashion, time since the birth of the previous sibling $(P R E V)$ is specified as follows :

$$
\left.\operatorname{Ln} h_{i j}^{P R E V(} t, \eta_{j}\right)=\gamma_{0}+\gamma_{1} Z_{P j}(t)+\gamma_{2} X_{P i j}(t)+\gamma_{3} T(t)+\eta_{j}+u_{P i j}
$$

The baseline hazard for each birth spacing equation is defined as piecewise linear splines which depends on two nodes. We have defined two nodes as 12 and 24 months as we find that the mortality risks are higher within the first two years of a child's life. Using these two nodes, we create three variables, namely, if spacing is 12 months or less, greater than 12 months but less than or equal to 24 months, and greater than 24 months.

Each birth spacing hazard equation depends on both individual and parental/ household characteristics, with some identifying variables between the two (see Appendix 1 for the definitions of these variables). Among the variables present in both the spacing equations, we include mother's age at first birth ${ }^{\text {xix }}$ and mother's literacy. Mother's age at first birth is a good measure of fecundity while mother's literacy is widely found to reduce fertility. We also include a binary variable indicating delivery problems in previous births, if any. This is likely to affect both spacing equations. Variation in household wealth is controlled by including ownership of land and whether the household lives in a brick house.

The choice and use of current contraceptives are important determinants of birth spacing in many cases, though, they are chosen by the couple in question and therefore, could not be treated as exogenous. Hence we use proxies that can reflect use of contraception in our sample. There is evidence that contraception use is rather limited among the Muslim couples in our sample, thus the binary variable Muslim could capture the couple's attitude towards modern contraception. ${ }^{\mathrm{xx}}$ We use two other binary variables, namely, ownership of a radio and a television, to indicate couple's awareness towards contraception through media 
advertisements. As with the mortality equation, we include the characteristics of the children already born, for example, whether the first child is a female and if the first child is dead.

\section{Identification}

Identification is achieved by the recursive structure of the model and the implied covariance restrictions implied by the correlated fixed effects. In a sequential framework, prior spacing is important for the posterior spacing decision and mortality of the context child and not vice versa. This is because timing of these two spacing decisions is separated by the birth of the context child. Once the child is born, parents can only move forward to plan for posterior spacing, taking account of prior spacing experience (and cannot go backward in time to revise the prior spacing decision already taken before the birth of the context child).

In addition, there are some differences in the lists of other regressors between the equations. Whether the current child is one of the twins (Twin) is important for posterior spacing decision, but not for the prior spacing of the context child (because parents cannot know before conception whether the child is a twin). Hence, Twin is included only in the posterior spacing equation. There are also some variables identifying the mortality equation. Ownership of radio and television is included only in the spacing equations as indicators of parental awareness of modern contraception. While some may argue that these are also household assets and could go in all three equations. But the fact remains that ownership of brick-built house and land would proxy for the ownership of any other valuable assets in the survival equation. Secondly, the binary variable indicating delivery problems at previous births is included in the spacing equations though not in the mortality equation because we believe that this variable is more likely to affect child health indirectly through spacing. If, however, there is a genetic problem attached to delivery problem of a particular couple and if it repeats itself for each birth, this would enter the mortality equation through the unobserved mother-specific heterogeneity factor that we explain below.

\section{Parent-specific unobserved heterogeneity}

Since decisions on both birth interval (prior and/or posterior) and investment for child survival are made by the same woman (or couple), the residuals are likely to be correlated across decisions. We therefore have two components in each residual: a mother/family specific $(\eta, \varepsilon, \delta)$ component and a child specific $\left(u_{N}, u_{P}, u_{M}\right)$ component respectively in the posterior and prior birth spacing and the mortality equations. The family- 
specific components are constant across all births of a given mother. Each is assumed to be distributed normally with zero means and variances $\sigma_{\eta}^{2}, \sigma_{\varepsilon}^{2}$ and $\sigma_{\delta}^{2}$ respectively. The childspecific components are normally, independently and identically distributed with unit variance, and independent of the family specific components. The correlation coefficients between the errors in the different equations are shown by $\rho_{K L}$ where $K, L=\mathcal{E}, \eta, \delta$ respectively for posterior, prior spacing and mortality equations.

\section{Joint Estimation}

Joint estimation of the spacing hazard and the child mortality probit equations is based on maximization of the joint marginal likelihood function obtained by integrating the product of conditional likelihood functions over the range of unobservables, weighted by the joint density function of unobservables (a la Panis and Lillard, 1994; 1995). The conditional likelihoods are the probabilities of observed outcomes (the birth spacing hazard and child mortality probit equation for each child in the sample), conditional on the vector of unobserved heterogeneity components $(\eta, \mathcal{E}, \delta)$. Thus when prior (PREV) and posterior (NEXT) spacing are treated as endogenous in the child mortality probit regression, the joint marginal likelihood function is written as:

$$
\iint_{\varepsilon_{i}} \int_{i} \int_{\delta_{i}}\left[\Pi L^{n}\left(\varepsilon_{i}\right) \prod L^{P}\left(\eta_{i}\right) \prod L^{S}\left(\delta_{i}\right)\right] f\left(\varepsilon_{i}, \eta_{i}, \delta_{i}\right) d \varepsilon_{i} d \eta_{i} d \delta_{i}
$$

where $f\left(\varepsilon_{i}, \eta_{i}, \delta_{i}\right)$ is the joint normal distribution of the unobserved heterogeneity components characterised as:

$$
\left(\begin{array}{l}
\varepsilon \\
\eta \\
\delta
\end{array}\right) \sim N\left[\left(\begin{array}{l}
0 \\
0 \\
0
\end{array}\right),\left(\begin{array}{ccc}
\sigma_{\varepsilon}^{2} & \cdot & \cdot \\
\rho_{\varepsilon \eta} \sigma_{\varepsilon} \sigma_{\eta} & \sigma_{\eta}^{2} & . \\
\rho_{\varepsilon \eta} \sigma_{\varepsilon} \sigma_{\eta} & \rho_{\eta \delta} \sigma_{\eta} \sigma_{\delta} & \sigma_{\delta}^{2}
\end{array}\right)\right]
$$

The model is estimated using Full Information Maximum Likelihood (FIML).

\section{RESULTS}

Tables $3 \mathrm{~A}, 3 \mathrm{~B}$ and $3 \mathrm{C}$ report separate estimates by gender of the child mortality (probit) equation and the spacing (hazard) equations. For completeness, we include 'baseline' estimates that ignore the family specific effect ('the no-heterogeneity' results). For each gender, we also present estimates assuming alternatively that the family-specific effects are uncorrelated and correlated. The same factors are significant in both uncorrelated and correlated estimates so the results are not qualitatively sensitive to this assumption (though 
these results differ somewhat between male and female children). The magnitudes of most of the estimates are approximately the same in each set of results while the value of the $\log$ likelihood function is higher for the correlated estimates.

The cross-correlations between the errors in the hazards and the mortality equation in Table $3 \mathrm{~A}$ are highly significant for both male and female children; so we concentrate on interpreting these correlated results. Later we shall demonstrate that the uncorrelated estimates can underestimate the probability of death. The negative values of the correlation coefficients suggest that unobserved factors that increase the hazards of prior or posterior birth tend to raise the chance of a child dying. This is consistent with our basic hypothesis that the smaller the interval between births the higher is the chances of (mortality). The rest of the analysis therefore concentrates on the correlated estimates.

\section{Estimates of Child Mortality}

Table 3B presents the estimates of the child mortality equation. The correlated estimates of mortality confirm our central hypotheses that an increase in the length of time either since the birth of the previous child or to the birth of the next child lowers the chance of the child dying in the first 5 years of life. Similar results are obtained from the alternative mortality hazard specification, which are summarised in Appendix Table A2.1. Secondly, being one of the twins increases the risks of mortality for both male and female children in our sample, again emphasizing the aspect of competition for limited resources both inside and outside the mother's womb. Death of the first child too increases the mortality risks of subsequent female children, perhaps suggesting some pro-male bias in response to this kind of tragedy. Pro-male bias is evident in other respects as well. For example, boys (and not girls) from families where the first child is a female, are more likely to survive. Thus sibling age and gender composition plays a central role in explaining child mortality. Role of mother's education is confirmed since both male and female children of literate mothers are

significantly less likely to die. Among the assets variables, boys living in brick houses are more likely to survive though none of the asset variables are significant for the girls. Religion may also be important as Muslim boys are significantly less likely to die, again suggesting some pro-male bias prevalent in the Muslim community.

After controlling for all other factors, living in a rural region has however no significant effect on child mortality. Even if individuals living in rural areas are less well-off and have poorer access to public health facilities, they do not fare worse than those in towns and cities. The latter may be facilitated by the availability of certain local public goods like 
common pastures or cleaner air so that the net effect of living in a rural region is not necessarily negative. Or it may simply reflect the fact the rural location at the time of the survey cannot simply capture the effect of location at the time of the birth of the child.

Correlated probit estimates of mortality (Table 3B) are compared with the corresponding correlated hazard estimates of mortality (Appendix 2, Table A2.1). These mortality hazard estimates too support our central hypotheses that twin birth as well as shorter prior and posterior spacing enhances the mortality hazard for both male and female children in our sample. Secondly, Appendix 2 Table A2.2 replaces spacing hazard equations by the discrete spacing (prior and posterior) variables, jointly estimated with the mortality probit equation. This specification allows us to explore the aspect of non-linearity, if any, in the relationship between spacing and child mortality. In doing so, we introduce three sets of discrete variables for each of prior (PREV) and posterior (NEXT) spacing :

PREV2: 1 if 12 months $<$ Prev <=24 months ; NEXT2: 1 if 12 months $<$ Next $<=24$ months;

PREV3: 1 if 24 months $<$ Prev $<=60$ months; NEXT3: 1 if 24 months $<$ Next $<=60$ months;

PREV4: 1 Prev >60 months; NEXT4: 1 Next >60 months

So the reference category in each case relates to spacing less than or equal to 12 months. These results as summarised in Appendix 2 Table A2.2 again corroborate our central hypotheses, though do not indicate presence of any non-linearity. Taken together, we could suggest that longer spacing (prior and posterior), i.e., less competition among prior and posterior siblings, significantly lowers child mortality in our sample.

\section{Estimates of Birth Spacing}

The 'baseline' hazard of having a subsequent sibling is greatest in the first 12 months. It then declines gradually from 12-24 months and then after 24 months (note that the coefficients of DURSP1, DURSP2 and DURSP3 gradually decline). The various socioeconomic variables affect prior and posterior spacing differently. For example, the posterior hazard is lower and the prior hazard is higher for boys born to literate mothers. An asymmetric wealth effect is observed: the posterior hazard is lower and prior hazard higher for more wealthy households living in a brick house, though these effects are only significant for male children. Mother's age at first birth is important for both boys and girls. Boys and girls born to older mothers tend to have lower posterior hazard. Previous delivery problems of the mother significantly lower the posterior hazard of female children, but is not important for boys. As with mortality, household religion tends to be more important for girls: Muslim 
girls are more likely to face a higher prior hazard than other girls. Regional location (e.g., rural) however remains insignificant in the spacing equation as well.

Among the sibling composition variables, the hazard of having a subsequent sibling is higher if the first child is a female and the effect is significant only for the male children. Death of the first child however significantly shortens the prior spacing while longer prior spacing significantly lowers posterior hazard for both male and female children.

It has widely been documented that mother's literacy and household assets may affect birth interval. A particular advantage of our modelling strategy is that these sequential estimates allow us to establish how these factors may affect prior and posterior spacing differently. We show that mother's literacy and household assets may lower the hazard of subsequent birth, but may still increase the hazard of prior birth. The essential implication is that these variables may be more effective to reduce fertility once a target family size is achieved. While the direct effects of prior and posterior spacing on child mortality are symmetric, indirect effects of these economic variables on spacing (prior and posterior) and therefore on child mortality are asymmetric.

\subsection{Inferences}

Thus these correlated estimates of birth spacing and child survival generally lend support to the central hypothesis of sibling rivalry in that shorter birth interval (prior and posterior) and twin births significantly enhance mortality risks among 0-5 year old male and female children in a sequential framework. ${ }^{\mathrm{xxi}}$ In general the parameter estimates from uncorrelated (where birth spacing variables are treated as exogenous) and correlated (corrected estimates) models indicate similar pattern of results though uncorrelated estimates are likely to suffer from endogeneity bias. In order to examine the extent of the bias in the uncorrelated estimates, we finally compare the predicted probability of mortality for the middle order children, as summarised in Table 5. These predicted probability estimates not only suggest a significantly higher mortality risks if consecutive children are born within 12 months and if the current child is one of the twins, but also that the uncorrelated estimates tend to underestimate the mortality risks in our sample. It also highlights the asymmetry between prior and posterior spacing between male and female children in our sample. In particular, if the context child is male, shorter prior/posterior spacing does not make much difference in the mortality risks (the risk is only slightly higher if the prior spacing is shorter). If however the context child is a female, mortality risks are substantially higher if the posterior spacing is less than a year than if the prior spacing is less than a year. These 
estimates further substantiate the role of siblings on child mortality in resource constrained households with pro-male bias.

Finally, we compare our preferred estimates to the corresponding fixed effects logit estimates (based on conditional likelihood), the analogue of the fixed effects estimates of Rosenzweig (1986). These estimates are summarised in Appendix 2 Table A2.3. Motherspecific characteristics are dropped in the fixed effects estimates shown in Table A2.3 but the fixed effects are qualitatively similar to the correlated estimates shown in Table 3B. In particular, like the correlated estimates, these fixed effects estimates support our hypotheses that (a) longer prior and posterior spacing lowers mortality rates. (b) Twin birth is detrimental to child survival. Results (a) and (b) are valid for both male and female children in the sample.

\section{CONCLUDING COMMENTS}

This paper examines the role of siblings on child survival in India and argues that competition among siblings for limited resources plays a significant role on child survival. Within a sequential framework, this means that, the health outcome of the current child not only depends on its older sibling's posterior spacing but also on the younger sibling's prior spacing. Twins are a natural outcome and birth of a twin imposes strain on parental resources which in turn is likely to affect posterior spacing of the current child (i.e., younger sibling's prior spacing). Parental allocation of resources is further complicated if parents are characterised by the pro-male bias. Thus in addition to the prior and posterior spacing and birth of twins, gender composition (measured by gender of the current as well as the first child) become important for child survival.

The empirical analysis based on the recent NFHS data from West Bengal employs a likelihood system estimation technique to determine prior and posterior spacing hazards and mortality probit (or hazard) equations jointly as correlated processes, allowing for mother/parents specific unobserved heterogeneity among male and female children. The explanatory variables are chosen to reduce the endogeneity bias as far as practicable and include among various individual and household specific characteristics, prior and posterior birth spacing, if the child is one of the twin and also gender of the first child respectively as measures of age and gender composition of siblings. These devices allow us to estimate the effects of sibling composition, corrected for the possible endogeneity bias. Predicted probability estimates substantiate the bias generated by ignoring the possible correlation between the two decisions. 
Given the values of other variables, we interpret our results as showing that competition for limited resources is an important part of any explanation of child mortality in West Bengal. Direct sibling rivalry in a sequential framework is captured by the prior and posterior birth spacing. As the birth spacing increases, the chances of survival improve for the context child perhaps because parents are able to devote more time and effort to bringing that child through his or her critical early years. Twin birth too significantly enhances the mortality risks of both male and female children while risk of having a subsequent sibling is higher for boys if the first child is a female.

We compare our correlated system estimates with alternative estimates including the fixed effects logit estimates of child mortality mimicking Rosenzweig's fixed effects analysis. These fixed-effects estimates turn out to be qualitatively similar to those obtained from the correlated recursive system of equations, thus establishing the robustness of our estimates. Our analysis also suggests that the uncorrelated estimates tend to underestimate the effects of prior and posterior spacing on child mortality. There is thus a significant potential for reducing child mortality even in a state like West Bengal (with moderate level of female literacy among the Indian states) and this could be achieved by encouraging use of modern non-terminal methods of contraception for spacing birth. The potential effects of reducing child mortality by spacing child birth could be far more in some other Indian states with lower levels of female literacy. 


\section{REFERENCES}

Anderson, KH (1983) 'The Determinants of Fertility, Schooling and Child Survival in Guatemala', International Economic Review 24:567-589.

Basu, A.M., Basu, K (1991) 'Women's Economic Roles and Child Survival : The Case of India' Health Transition Review, 1:83-103.

Becker, G (1965) ‘A Theory of Allocation of Time’, Economic Journal, 75:493-517.

Cambridge, MA.

(1991) A Treatise on the Family Enlarged edition, Harvard University Press,

Black, SP, Devereux Jand Salvanes KG (2004) 'The More the Merrier: The effect of Family Composition on Children Education', IZA DP. No. 1269, Bonn, Germany.

Bourne, K, Walker GM (1991) 'The Differential Effect of Mother's Education on Mortality of Boys and Girls in India', Population Studies, 45.

Brien, MJ, Lillard LA (1994) 'Education, Marriage, and First Conception in Malaysia.' Journal of Human Resources 29(4):1167-1204.

Butcher C, Case A (1994) 'The Effect of Sibling Sex Composition on Women's Education and Earnings, Quarterly Journal of Economics, 109(3): 531-63.

Chamberlain G, Griliches, Z (1975) 'Unobservables with a Variance Components Structure: Ability, Schooling and the Economic Success of Brothers', International Economic Review, $16(2): 422-449$

Choe MK, Diamond I, Steele F and Kim SK (1998) 'Son Preference, Family Building Process and Child Mortality' in Too Young to Die: Genes or Gender?' ST/ESA/SER.A/155, pp. 208-222. United Nations, New York.

Cleland J, Hobcraft J (1985) Reproductive Change in Developing Countries, Oxford University Press.

Curtis SL, Diamond I, McDonald JW (1993) 'Birth Interval and Family Effects on Postneonatal Mortality in Brazil', Demography, 30 (1): 33-43.

Dasgupta M (1987) 'Selective discrimination against female children in rural Punjab', Population and Development Review, 13.

Dasgupta M (1997) 'Socio-economic Status and Clustering of Child Deaths in Rural Punjab', Population Studies, 51(2): 191-202.

Drèze J, Sen A (1995) India: Economic Development and Social Opportunity, Oxford: Clarendon Press.

Garg A, Morduch, J (1998) 'Sibling Rivalry and the Gender Gap: Evidence from Child Health Outcomes in Ghana' Journal-of-Population-Economics, 11(4): 471-93.

Hobcraft JN., McDonald JW, Rutstein SO (1985) 'Demographic Determinants of Infant and Early Child Mortality: A Comparative Analysis', Population Studies, 39(3): 363-85

Kishor S (1993). 'May God Give Sons to All: Gender and Child Mortality in India', American Sociological Review, 58: 247-65.

Kynch J, Sen AK (1983) 'Indian women: well-being and survival', Cambridge Journal of Economics, 7: 363-80. 
Lillard LA, Willis RJ (1994) 'Intergenerational Educational Mobility: Effects of Family and State in Malaysia', Journal of Human Resources, 29(4): 1126 - 66.

Maitra P (2004) 'Parental Bargaining, Health Inputs and Child Mortality in India', Journal of Health Economics:

Makepeace G, Pal, S (2006). Effects of Birth Interval on Child Mortality: Evidence from A Sequential Analysis' World Health and Population January: 1-14.

Muhuri PK, Preston, SH (1991) 'Effects of Family Composition on Mortality Differentials by Sex among Children in Matlab, Bangladesh', Population and Development Review, 17(3): 415-34.

Pal S (1999) 'An Analysis of Childhood Malnutrition in Rural India: Role of Gender, Income and Other Household Characteristics', World Development: 1151-1171.

Pal S, Makepeace G (2003) 'Current Contraceptive Use in India: Has the Role of Women's Education been Over-Emphasized?' European Journal of Development Research,15(1).

Panis CWA, Lillard LA (1994) 'Health Inputs and Child Mortality: Malaysia', Journal of Health Economics 13:455-89.

Panis CWA, Lillard LA (1995) 'Child Mortality in Malaysia: Explaining Ethnic Differences and the Recent Decline', Population Studies 49: 463-79.

Parish W, Willis, R (1994) 'Daughters, Education and Family Budgets: Taiwan Experiences', Journal of Human Resources 28 (4): 862-98.

Rosenzweig M (1986) 'Birth Spacing and Sibling Inequality: Asymmetric Information within the Family', International Economic Review: 55-76.

Rosenzweig M, Schultz TP (1982) 'Market Opportunities, Genetic Endowments and intrafamily resource distribution, American Economic Review, 74:215-235.

Rosenzweig M, Wolpin KI (2000) 'Natural 'Natural Experiments' in Economics', Journal of Economic Literature: 827-74.

Sathar Z (1992) 'Child Survival and Changing Fertility Patterns in Pakistan', Pakistan Development Review: 699-713.

Sen AK, Sengupta S (1983) 'Malnutrition of Rural Children and Sex Bias', Economic and Political Weekly: 855-64.

Sengupta S, Gazdar, H (1997) in Drèze, J.P. and A.K. Sen (ed.) Indian Development : Selected Regional Perspectives, WIDER studies in Development Economics, Clarendon Press, Oxford.

Thomas D, Strauss J (1992) 'Prices, Infrastructure, Household Characteristics and Child Height', Journal of Development Economics: 301-331.

Wolpin K (1984) 'An Estimable Dynamic Stochastic Model of Fertility and Child Mortality', Journal of Political Economy: 852-74. 
Table 1A. Comparison of West Bengal with important Indian states

\begin{tabular}{|c|c|c|c|c|c|c|c|}
\hline \multirow{3}{*}{ States } & \multirow{3}{*}{$\begin{array}{l}\text { Popln. } \\
\text { (in } \\
\text { mn) } \\
1991\end{array}$} & \multirow{3}{*}{$\begin{array}{l}\text { Female } \\
\text { literacy } \\
\text { Age } 7+ \\
1991\end{array}$} & \multirow{3}{*}{$\begin{array}{l}\text { Female } \\
\text { labour } \\
\text { participn } \\
1991\end{array}$} & \multirow{3}{*}{$\begin{array}{l}\text { Total } \\
\text { fertilit } \\
\text { y rate }\end{array}$} & & \multicolumn{2}{|c|}{$\begin{array}{l}\text { Death rate, age } \\
0-4.1991 \\
\text { (per 1000) }\end{array}$} \\
\hline & & & & & $\begin{array}{l}\text { Infant } \\
\text { Mortali } \\
\text { ty } \\
\text { Rate } \\
\text { per } \\
1000\end{array}$ & Female & Male \\
\hline & & & & & $\begin{array}{l}1990- \\
92\end{array}$ & & \\
\hline Kerala & 29 & 86.2 & 12.8 & 1.8 & 17 & 4.1 & 4.5 \\
\hline Punjab & 20 & 50.4 & 2.8 & 3.1 & 57 & 18.4 & 15.6 \\
\hline Haryana & 16 & 40.5 & 6.0 & 4.0 & 71 & 23.8 & 22.3 \\
\hline Maharashtra & 78 & 52.3 & 26.5 & 3.0 & 59 & 16.7 & 15.9 \\
\hline AP & 67 & 32.7 & 30.1 & 3.0 & 71 & 20.2 & 22.3 \\
\hline Tamil Nadu & 56 & 51.3 & 25.1 & 2.2 & 58 & 15.3 & 16.9 \\
\hline WB & 68 & 46.6 & 8.0 & 3.2 & 66 & 20.8 & 20.4 \\
\hline India & 846 & 39.3 & 16.0 & 3.6 & 80 & 27.5 & 25.6 \\
\hline
\end{tabular}

Note: AP: Andhra Pradesh; WB: West Bengal

Source: Drèze and Sen(1995);

Government of India web site: www.nic.in/mohfw/popindi.html

Table 1B. Current contraception use among various religious groups

\begin{tabular}{|c|c|c|c|}
\hline & \multicolumn{3}{|c|}{ \% of the particular religious group } \\
\hline Current method of contraception & Hindu & Muslim & Other \\
\hline None & 44 & 60 & 47 \\
\hline $\begin{array}{c}\text { Traditional non-terminal } \\
\text { (abstinence/withdrawal) }\end{array}$ & 18 & 19 & 21 \\
\hline $\begin{array}{c}\text { Modern non-terminal } \\
\text { (pills, condoms, etc) }\end{array}$ & 6 & 6 & 2 \\
\hline $\begin{array}{c}\text { Sterilisation } \\
\text { (male \& female) }\end{array}$ & 32 & 15 & 30 \\
\hline
\end{tabular}


Table 2. Effects of sibling composition on child mortality

(Percentages in categories)

\begin{tabular}{|l|l|l|l|l|l|l|}
\hline $\begin{array}{l}\text { Birth interval } \\
\text { months }\end{array}$ & $\begin{array}{l}\text { Birth } \\
\text { order }\end{array}$ & $\begin{array}{l}\text { Gender of } \\
\text { first born }\end{array}$ & $\begin{array}{l}\text { First } \\
\text { born } \\
\text { died }\end{array}$ & Male & Female & All \\
\hline All children & All & All & No & 13.3 & 13.2 & 13.2 \\
\hline 12 or less & All & All & No & 16.4 & 14.5 & 15.5 \\
\hline 12 or less & Not first & All & No & 28.8 & 29 & 29 \\
\hline 12 or less & Not first & Female & No & 27.3 & 35.7 & 31.3 \\
\hline 12 or less & Not first & All & Yes & 34.3 & 34.6 & 34.5 \\
\hline$>12 \&<=24$ & All & All & No & 12.6 & 13.6 & 13.1 \\
\hline$>12 \&<=24$ & Not first & All & No & 18.8 & 20.3 & 19.5 \\
\hline$>12 \&<=24$ & Not first & Female & No & 16.1 & 21.8 & 19.0 \\
\hline$>12 \&<=24$ & Not first & All & Yes & 21.8 & 23.4 & 22.6 \\
\hline$>24 \&<=60$ & All & All & No & 8.0 & 7.0 & 7.5 \\
\hline$>24 \&<=60$ & Not first & All & No & 12.4 & 10.9 & 11.7 \\
\hline$>24 \&<=60$ & Not first & Female & No & 12.5 & 10.0 & 11.2 \\
\hline$>24 \&<=60$ & Not first & All & Yes & 15.9 & 16.2 & 16.1 \\
\hline
\end{tabular}


Table 3A. Structure of unobserved heterogeneity

\begin{tabular}{ccccc} 
& \multicolumn{2}{c}{ Uncorrelated } & \multicolumn{2}{c}{ Correlated } \\
& Male & Female & Male & Female \\
$\sigma_{\eta}$ & $0.2615 * * *$ & $0.2591 * * *$ & $0.5330 * * *$ & $0.4231 * * *$ \\
& 0.0657 & 0.0583 & 0.05 & 0.0457 \\
$\sigma_{\varepsilon}$ & $0.6242 * * *$ & $0.5569 * * *$ & $0.5944 * * *$ & $0.4661 * * *$ \\
& 0.0382 & 0.0393 & 0.0424 & 0.0409 \\
$\sigma_{\delta}$ & $0.3447 * * *$ & $0.4248 * * *$ & $0.3390 * * *$ & $0.3713 * * *$ \\
& 0.0961 & 0.0706 & 0.1055 & 0.0801 \\
$\rho(\eta, \varepsilon)$ & & & $-0.8953 * * *$ & -0.8941 \\
& & & & $* * *$ \\
$\rho(\eta, \delta)$ & & & 0.0633 & 0.1331 \\
& & & $0.2221 * *$ & $0.2129 *$ \\
$\rho(\varepsilon, \delta)$ & & & 0.0822 & 0.1278 \\
& & & $0.2246 * * *$ & $0.3812 *$ \\
& & & 0.0508 & 0.2216
\end{tabular}


Table 3B. Mortality Probit Equation (Correlated estimates)

\begin{tabular}{|c|c|c|}
\hline & $\begin{array}{c}\text { Male } \\
\text { With het }\end{array}$ & $\begin{array}{c}\text { Female } \\
\text { With het }\end{array}$ \\
\hline Intercept & 0.02 & $\begin{array}{c}-0.5666 \\
* * *\end{array}$ \\
\hline \multirow[t]{2}{*}{ Mother literate } & $\begin{array}{c}0.1911 \\
-0.1674 * *\end{array}$ & $\begin{array}{c}0.1658 \\
-0.2510 \\
* * *\end{array}$ \\
\hline & 0.0762 & 0.0754 \\
\hline Twin & $\begin{array}{c}1.2551 * * * \\
0.1969\end{array}$ & $\begin{array}{c}1.3386 \text { *** } \\
0.1822\end{array}$ \\
\hline First child is a female & $\begin{array}{c}-0.1013 * \\
0.054\end{array}$ & $\begin{array}{c}-0.0525 \\
0.0642\end{array}$ \\
\hline First child died & $\begin{array}{l}0.1066 \\
0.0695\end{array}$ & $\begin{array}{c}0.1714 * * \\
0.0728\end{array}$ \\
\hline Time since previous birth & $-0.0195 * * *$ & $\begin{array}{c}-0.0105 \\
* * *\end{array}$ \\
\hline \multirow[t]{2}{*}{ Time to next birth } & $\begin{array}{c}0.0034 \\
-0.0127 * * *\end{array}$ & $\begin{array}{c}0.0032 \\
-0.0077 \\
* * *\end{array}$ \\
\hline & 0.0025 & 0.0022 \\
\hline Agricultural land & $\begin{array}{c}-0.0288 \\
0.0668\end{array}$ & $\begin{array}{c}-0.0013 \\
0.0678\end{array}$ \\
\hline Pucca & $\begin{array}{c}-0.1954 * \\
0.1164\end{array}$ & $\begin{array}{c}-0.1445 \\
0.1185\end{array}$ \\
\hline Muslim & $\begin{array}{c}-0.2082 * * * \\
0.0676\end{array}$ & $\begin{array}{c}-0.0099 \\
0.0684\end{array}$ \\
\hline Rural & $\begin{array}{l}0.038 \\
0.095\end{array}$ & $\begin{array}{l}0.0717 \\
0.0966\end{array}$ \\
\hline
\end{tabular}

Note: Standard errors are shown below. Levels of significance: $*_{-} 10 \%$; ** $*_{-} \%$; ***-1\% 
Table 3C. Prior and posterior spacing, correlated estimates

\begin{tabular}{|c|c|c|c|c|}
\hline & \multicolumn{2}{|c|}{ Male } & \multicolumn{2}{|c|}{ Female } \\
\hline & $\begin{array}{l}\text { Posterior } \\
(N E X T) \\
\text { With het }\end{array}$ & $\begin{array}{c}\text { Prior } \\
(P R E V) \\
\text { With het }\end{array}$ & $\begin{array}{c}\text { Posterior } \\
(N E X T) \\
\text { With het }\end{array}$ & $\begin{array}{c}\text { Prior } \\
(P R E V) \\
\text { With het }\end{array}$ \\
\hline $0-12$ months & $\begin{array}{c}0.6817 * * * \\
0.1069\end{array}$ & $\begin{array}{c}0.6701 * * * \\
0.0936\end{array}$ & $\begin{array}{c}0.7166 * * * \\
0.1237\end{array}$ & $\begin{array}{c}0.8129 * * * \\
0.1011\end{array}$ \\
\hline 12-24 months & $\begin{array}{c}0.1587 * * * \\
0.0076\end{array}$ & $\begin{array}{c}0.1445 * * * \\
0.0068\end{array}$ & $\begin{array}{c}0.1471 * * * \\
0.0072\end{array}$ & $\begin{array}{c}0.1438 * * * \\
0.0069\end{array}$ \\
\hline$>24$ months & $\begin{array}{c}0.0070 * * * \\
0.0018\end{array}$ & $\begin{array}{c}0.0114 * * * \\
0.0021\end{array}$ & $\begin{array}{c}-0.0017 \\
0.0019\end{array}$ & $\begin{array}{c}0.0106 * * * \\
0.002\end{array}$ \\
\hline Intercept & $\begin{array}{c}-12.6949 \\
* * *\end{array}$ & $-12.4216 * * *$ & $-12.7705 * * *$ & $-13.7023 * * *$ \\
\hline & 1.2682 & 1.1066 & 1.4678 & 1.1893 \\
\hline Previous delivery problems & $\begin{array}{c}-0.1021 \\
0.1219\end{array}$ & $\begin{array}{l}0.0748 \\
0.1275\end{array}$ & $\begin{array}{c}-0.1457 * \\
0.0886\end{array}$ & $\begin{array}{l}0.0462 \\
0.0992\end{array}$ \\
\hline Age at first birth & $\begin{array}{c}-0.0153 * \\
0.0089\end{array}$ & $\begin{array}{l}0.0006 \\
0.0087\end{array}$ & $\begin{array}{c}-0.0202 * * \\
0.0092\end{array}$ & $\begin{array}{c}-0.0251 * * * \\
0.0081\end{array}$ \\
\hline Mother literate & $\begin{array}{c}-0.083 * \\
0.0417\end{array}$ & $\begin{array}{l}0.0683^{*} \\
0.04039\end{array}$ & $\begin{array}{l}0.0991 \\
0.0609\end{array}$ & $\begin{array}{l}0.0211 \\
0.0538\end{array}$ \\
\hline Twin & $\begin{array}{c}0.0166 \\
0.194\end{array}$ & & $\begin{array}{l}0.1793 \\
0.1255\end{array}$ & \\
\hline First child is female & $\begin{array}{c}0.0950 * * \\
0.0484\end{array}$ & $\begin{array}{l}0.0309 \\
0.0511\end{array}$ & $\begin{array}{c}-0.0138 \\
0.0474\end{array}$ & $\begin{array}{l}0.0468 \\
0.0462\end{array}$ \\
\hline First child died & $\begin{array}{l}0.0356 \\
0.0569\end{array}$ & $\begin{array}{c}0.1535 * * * \\
0.0567\end{array}$ & $\begin{array}{c}-0.0588 \\
0.0555\end{array}$ & $\begin{array}{c}0.1005 * \\
0.0518\end{array}$ \\
\hline Time since previous birth & $\begin{array}{c}-0.0038 * \\
0.002\end{array}$ & & $\begin{array}{c}-0.0059 * * * \\
0.0019\end{array}$ & \\
\hline Agricultural land & $\begin{array}{l}0.0277 \\
0.0514\end{array}$ & $\begin{array}{l}0.0464 \\
0.0527\end{array}$ & $\begin{array}{l}-0.0317 \\
-0.0516\end{array}$ & $\begin{array}{l}-0.0295 \\
-0.0499\end{array}$ \\
\hline Pucca & $\begin{array}{c}-0.1237 * \\
0.0699\end{array}$ & $\begin{array}{c}0.1276^{*} \\
0.0686\end{array}$ & $\begin{array}{l}-0.0951 \\
-0.0894\end{array}$ & $\begin{array}{l}-0.0558 \\
-0.0778\end{array}$ \\
\hline
\end{tabular}




\begin{tabular}{lcccc} 
Radio & 0.0161 & 0.0083 & -0.0765 & 0.0062 \\
& 0.0551 & 0.0552 & -0.0538 & -0.0505 \\
Television & -0.0315 & -0.0404 & -0.0746 & 0.0081 \\
\multirow{2}{*}{ Muslim } & 0.0979 & 0.112 & -0.1035 & -0.1011 \\
\multirow{2}{*}{ Rural } & 0.0534 & 0.0416 & 0.0362 & $0.0828 *$ \\
& 0.051 & 0.0534 & -0.0504 & -0.0481 \\
& -0.0244 & -0.0934 & -0.028 & -0.0152 \\
Ln-L & 0.0722 & 0.0764 & -0.0721 & -0.0695 \\
& & & & \\
& -20901.5 & -20901.52 & -21041.3 & -21041.34
\end{tabular}

Note: Standard errors are shown below. Levels of significance: $*_{-} 10 \% ; * *_{-} 5 \% ; * *_{-} 1 \%$ 
Table 4: Predicted probability of child mortality for middle-order children

\begin{tabular}{|c|c|c|}
\hline & Uncorrelated & Correlated \\
\hline \multicolumn{3}{|c|}{ All children with mean characteristics } \\
\hline Male & 0.13 & 0.13 \\
\hline Female & 0.13 & 0.13 \\
\hline \multicolumn{3}{|c|}{ If prior birth interval $<=12$ months } \\
\hline Male & 0.22 & 0.25 \\
\hline Female & 0.12 & 0.16 \\
\hline \multicolumn{3}{|c|}{ If posterior birth interval $<=12$ months } \\
\hline Male & 0.21 & 0.24 \\
\hline Female & 0.67 & 0.69 \\
\hline \multicolumn{3}{|c|}{ If the child is a twin } \\
\hline Male & 0.59 & 0.69 \\
\hline Female & 0.39 & 0.41 \\
\hline
\end{tabular}




\section{Appendix 1: Variable definitions and summary statistics}

\section{Variable Definitions}

The data are taken from the National Family Health Survey (NFHS) 1992-93 household data for West Bengal.

The dependent variables are:

1 if died at age 5 or less

Time to death (in months) censored at

\section{Regression variables}

Continuous variables

Mother's age at birth of first child

Length of time (in months) since the birth of the previous child

Length of time (in months) to the birth of the next child

Binary variables

$\begin{array}{ll}\text { Mother is literate } & 1 \text { if the mother is literate } \\ \text { Twin } & 1 \text { if the child is a twin or a triplet } \\ \text { First child is female } & 1 \text { if the first sibling in the family is a } \\ \text { First child is dead } & 1 \text { if the first sibling in the family died } \\ \text { Delivery problem in the previous birth } 1 \text { if delivery problem } \\ \text { Radio } & 1 \text { if the household owns a radio } \\ \text { Television } & 1 \text { if the household owns a television } \\ \text { Agricultural land } & 1 \text { if owns land } \\ \text { Pucca } & 1 \text { if lives in a brick house }\end{array}$


Muslim

Rural

Male
1 if the family is Muslim

1 if the child lives in rural areas

1 if the child is male 
Table A1.1: Sample characteristics - means and standard deviations

\begin{tabular}{cccccccc} 
& \multicolumn{5}{c}{ Female } & & Male \\
& & Mean & Std Dev & & Mean & Std Dev \\
Mother's age at birth of first child & 3067 & 17.14803 & 2.630718 & 3044 & 17.06439 & 2.671485 \\
Mother is literate & 3067 & 0.297033 & 0.457026 & 3044 & 0.290079 & 0.453873 \\
Child is a twins/triplets & 3067 & 0.017933 & 0.132729 & 3044 & 0.020368 & 0.141279 \\
First child is a female & 3067 & 0.515814 & 0.499831 & 3044 & 0.494087 & 0.500047 \\
First child is dead & 3067 & 0.257255 & 0.437192 & 3044 & 0.268068 & 0.443026 \\
Delivery problem in previous birth & 3067 & 0.06195 & 0.241104 & 3044 & 0.050591 & 0.219198 \\
Time since birth of previous child & 3067 & 30.59374 & 14.84545 & 3044 & 30.5138 & 15.30044 \\
Time to the birth of next child & & & & & & \\
Ownership of land & 3067 & 0.546136 & 0.497948 & 3044 & 0.542707 & 0.498255 \\
Pucca (Owns a brick house) & 3067 & 0.108901 & 0.311566 & 3044 & 0.112681 & 0.316254 \\
Owns a radio & 3067 & 0.361265 & 0.480446 & 3044 & 0.361367 & 0.480475 \\
Owns a television & 3067 & 0.084773 & 0.27859 & 3044 & 0.086071 & 0.280515 \\
Muslim household & 3067 & 0.34431 & 0.47522 & 3044 & 0.367608 & 0.482233 \\
Lives in rural region & 3067 & 0.846104 & 0.360908 & 3044 & 0.832457 & 0.373521
\end{tabular}


Appendix 2

Table A2.1. Mortality hazard estimates

\begin{tabular}{|c|c|c|c|c|c|c|}
\hline & \multicolumn{4}{|c|}{ Uncorrelated estimates } & \multicolumn{2}{|c|}{$\begin{array}{l}\text { Correlated } \\
\text { estimates }\end{array}$} \\
\hline & $\begin{array}{l}\text { Male } \\
\text { No het }\end{array}$ & With Het & $\begin{array}{l}\text { Female } \\
\text { No het }\end{array}$ & With Het & $\begin{array}{l}\text { Male } \\
\text { With } \\
\text { Het }\end{array}$ & $\begin{array}{c}\text { Female } \\
\text { With } \\
\text { Het }\end{array}$ \\
\hline DUR03 & $\begin{array}{c}-1.3627 \\
* * *\end{array}$ & $-1.3459 * * *$ & $\begin{array}{c}-1.4946 \\
* * *\end{array}$ & $\begin{array}{c}-1.4641 \\
* * *\end{array}$ & $\begin{array}{c}-1.3667 \\
* * *\end{array}$ & $\begin{array}{c}-1.4872 \\
* * *\end{array}$ \\
\hline DUR36 & $\begin{array}{c}-0.0835 \\
0.1194\end{array}$ & $\begin{array}{l}-0.0852 \\
0.1185\end{array}$ & $\begin{array}{c}-0.0953 \\
0.2980 \\
* * *\end{array}$ & $\begin{array}{c}-0.0951 \\
0.2932 * * *\end{array}$ & $\begin{array}{c}-0.0868 \\
0.13\end{array}$ & $\begin{array}{c}-0.0989 \\
0.3201 \\
* * *\end{array}$ \\
\hline DUR6+ & $\begin{array}{c}-0.0811 \\
-0.0404 \\
* * *\end{array}$ & $\begin{array}{c}-0.0811 \\
-0.0399 * * *\end{array}$ & $\begin{array}{c}-0.0887 \\
-0.0355 \\
* * *\end{array}$ & $\begin{array}{c}-0.0881 \\
-0.0346 \\
* * *\end{array}$ & $\begin{array}{c}-0.0827 \\
-0.0393 \\
\text { *** }\end{array}$ & $\begin{array}{c}-0.0925 \\
-0.0360 \\
* * *\end{array}$ \\
\hline Intercept & $\begin{array}{l}-0.0048 \\
-0.2558\end{array}$ & $\begin{array}{c}-0.0048 \\
-0.3720 *\end{array}$ & $\begin{array}{c}-0.0045 \\
-0.7796 \\
* * *\end{array}$ & $\begin{array}{c}-0.0045 \\
-0.9128 \\
* * *\end{array}$ & $\begin{array}{l}-0.0049 \\
-0.099\end{array}$ & $\begin{array}{c}-0.0047 \\
-0.8740 \\
* * *\end{array}$ \\
\hline Mother is lterate & $\begin{array}{c}-0.1932 \\
-0.3012 \\
* * *\end{array}$ & $\begin{array}{c}-0.2174 \\
-0.2961 * *\end{array}$ & $\begin{array}{c}-0.1946 \\
-0.3906 \\
* * *\end{array}$ & $\begin{array}{c}-0.2302 \\
-0.4005 \\
* * *\end{array}$ & $\begin{array}{c}-0.2691 \\
-0.3311 \\
* * *\end{array}$ & $\begin{array}{c}-0.3137 \\
-0.3921 \\
* * *\end{array}$ \\
\hline Twin & $\begin{array}{c}-0.1115 \\
1.8285 * * *\end{array}$ & $\begin{array}{c}-0.1249 \\
2.0030 * * *\end{array}$ & $\begin{array}{c}-0.1084 \\
1.6669 \\
* * *\end{array}$ & $\begin{array}{c}-0.1251 \\
1.8768 * * *\end{array}$ & $\begin{array}{c}-0.1232 \\
1.9804 \\
* * *\end{array}$ & $\begin{array}{c}-0.1241 \\
1.8607 \\
* * *\end{array}$ \\
\hline First child is female & $\begin{array}{c}-0.1722 \\
-0.143\end{array}$ & $\begin{array}{l}-0.2097 \\
-0.1549\end{array}$ & $\begin{array}{c}-0.1531 \\
-0.068\end{array}$ & $\begin{array}{l}-0.2062 \\
-0.0652\end{array}$ & $\begin{array}{c}-0.2117 \\
-0.1753 \\
*\end{array}$ & $\begin{array}{l}-0.2042 \\
-0.0502\end{array}$ \\
\hline First child died & $\begin{array}{c}-0.0887 \\
0.1554 *\end{array}$ & $\begin{array}{c}-0.1031 \\
0.1793 *\end{array}$ & $\begin{array}{c}-0.0858 \\
0.2763 \\
* * *\end{array}$ & $\begin{array}{c}-0.1051 \\
0.2718 * *\end{array}$ & $\begin{array}{l}-0.1023 \\
0.1605\end{array}$ & $\begin{array}{c}-0.1057 \\
0.2599 \\
* *\end{array}$ \\
\hline Time since previous & $\begin{array}{l}-0.0925 \\
-0.0332\end{array}$ & $\begin{array}{c}-0.1086 \\
-0.0341 * * *\end{array}$ & $\begin{array}{l}-0.0968 \\
-0.0267\end{array}$ & $\begin{array}{l}-0.1194 \\
-0.0280\end{array}$ & $\begin{array}{l}-0.1082 \\
-0.0383\end{array}$ & $\begin{array}{c}-0.119 \\
-0.0270\end{array}$ \\
\hline
\end{tabular}




\begin{tabular}{lcccccc} 
birth & $* * *$ & & $* * *$ & $* * *$ & $* * *$ & $* * *$ \\
& -0.0036 & -0.0038 & -0.0038 & -0.004 & -0.0053 & -0.0054 \\
Time to next birth & -0.0227 & $-0.0231 * * *$ & -0.0207 & -0.0218 & -0.0259 & -0.0219 \\
& $-* * *$ & & $* * *$ & $* * *$ & $* * *$ & $* * *$ \\
\multirow{2}{*}{ Agricultural land } & -0.0032 & -0.0033 & -0.0028 & -0.0029 & -0.0042 & -0.0037 \\
& -0.0306 & -0.0432 & -0.0022 & -0.0093 & -0.0314 & -0.0189 \\
Pucca & -0.0916 & -0.1076 & -0.091 & -0.1118 & -0.1063 & -0.1104 \\
& -0.2508 & -0.2503 & -0.1366 & -0.1514 & -0.2863 & -0.1524 \\
Muslim & -0.1617 & -0.1817 & -0.17 & -0.1967 & -0.1805 & -0.1958 \\
& -0.3757 & $-0.3901 * * *$ & -0.0986 & -0.1019 & -0.4006 & -0.0901 \\
\multirow{2}{*}{ Rural } & $* * *$ & & & & $* * *$ & \\
& -0.0922 & -0.108 & -0.0911 & -0.1119 & -0.1085 & -0.1103 \\
ln-L & 0.0951 & 0.0786 & 0.1743 & 0.1401 & 0.0344 & 0.1231 \\
& -0.1351 & -0.1514 & -0.1279 & -0.1551 & -0.1501 & -0.1562 \\
& -2355.14 & -2350.86 & -2494.52 & -2486.32 & - & - \\
& & & & & 22028.9 & 22229.9
\end{tabular}

Note: Standard errors are shown below. Levels of significance: $*_{-} 10 \%$; $*_{-} 5 \%$; ***- $1 \%$ 
Table A2.2. Mortality probit estimates with discrete spacing variables

\begin{tabular}{|c|c|c|c|c|c|c|}
\hline & \multicolumn{4}{|c|}{$\begin{array}{l}\text { Uncorrelated } \\
\text { estimates }\end{array}$} & \multicolumn{2}{|c|}{ Correlated estimates } \\
\hline & Male & & Female & & Male & Female \\
\hline \multirow[t]{2}{*}{ Intercept } & $0.4579 * *$ & $\begin{array}{c}0.4704 \\
* *\end{array}$ & -0.0363 & -0.0105 & 0.3891 & -0.2873 \\
\hline & -0.1851 & -0.1992 & -0.1887 & -0.2223 & -0.2443 & -0.2302 \\
\hline \multirow[t]{2}{*}{ Mother is literate } & $\begin{array}{c}-0.1713 \\
* *\end{array}$ & $\begin{array}{c}-0.1708 \\
* *\end{array}$ & $\begin{array}{l}-0.2074 \\
* * *\end{array}$ & $\begin{array}{l}-0.2419 \\
* * *\end{array}$ & $-0.1670 * *$ & $\begin{array}{c}-0.2393 \\
* * *\end{array}$ \\
\hline & -0.0685 & -0.0754 & -0.0656 & -0.0804 & -0.0734 & -0.0786 \\
\hline \multirow[t]{2}{*}{ Twin } & $\begin{array}{l}1.2087 \\
* * *\end{array}$ & $\begin{array}{c}1.2512 \\
* * *\end{array}$ & $\begin{array}{c}1.1254 \\
* * *\end{array}$ & $1.2253 * * *$ & $\begin{array}{c}1.2282 \\
* * *\end{array}$ & $1.3303 * * *$ \\
\hline & -0.1683 & -0.1846 & -0.1444 & -0.1754 & -0.1929 & -0.177 \\
\hline \multirow[t]{2}{*}{ First child is female } & $-0.0938 *$ & -0.0961 & -0.0309 & -0.0367 & -0.0827 & -0.0567 \\
\hline & -0.0557 & -0.0622 & -0.0538 & -0.0671 & -0.0614 & -0.0659 \\
\hline \multirow[t]{2}{*}{ First child died } & 0.0899 & 0.0898 & $0.1497 * *$ & $0.1626 * *$ & $0.1297 *$ & $0.1824 * *$ \\
\hline & -0.0603 & -0.0676 & -0.06 & -0.0759 & -0.0667 & -0.0746 \\
\hline \multirow{2}{*}{$\begin{array}{l}\text { PREV2 } \\
\text { 12-24 mths }\end{array}$} & $\begin{array}{l}-0.2978 \\
* *\end{array}$ & $\begin{array}{c}-0.3034 \\
* *\end{array}$ & -0.0452 & -0.0522 & $-0.3158 * *$ & 0.0199 \\
\hline & -0.1319 & -0.1386 & -0.1444 & -0.1636 & -0.1409 & -0.1599 \\
\hline \multirow{3}{*}{$\begin{array}{l}\text { PREV3 } \\
24-60 \text { mths }\end{array}$} & -0.6341 & -0.6595 & -0.3606 & $-0.4087 * *$ & -0.5642 & -0.236 \\
\hline & & & & & & \\
\hline & -0.1274 & -0.1343 & -0.1448 & -0.1634 & -0.1455 & -0.1646 \\
\hline
\end{tabular}




$\begin{array}{lcccccc}\text { PREV4 } & -1.0967 & -1.1962 & -0.5383 & -0.6208 & -0.8931 & -0.0862 \\ >60 \text { mths } & * * * & * * * & * * * & * * * & * * * & \\ & -0.2417 & -0.2589 & -0.2086 & -0.2343 & -0.2997 & -0.2644 \\ \text { NEXT2 } & -0.7768 & -0.8012 & -0.6136 & -0.6998 & -0.8087 & -0.5451 \\ \text { 12-24 mths } & * * * & * * * & * * * & * * * & * * * & * * * \\ & -0.1404 & -0.1484 & -0.1214 & -0.1353 & -0.1531 & -0.1392 \\ \text { NEXT3 } & -1.0101 & -1.0496 & -0.9495 & -1.0722 & -1.0530 & -0.8824 \\ \text { 24-60 mths } & * * * & * * * & * * * & * * * & * * * & * * * \\ & -0.1374 & -0.1457 & -0.1212 & -0.1392 & -0.1568 & -0.1462 \\ \text { NEXT4 } & -1.1095 & -1.1476 & -1.0729 & -1.2099 & -1.1321 & -0.9157 \\ >60 \text { mths } & * * * & * * * & * * * & * * * & * * * & * * * \\ & -0.1835 & -0.1946 & -0.1677 & -0.1863 & -0.2208 & -0.2106 \\ \text { Land } & -0.0329 & -0.033 & -0.007 & 0.003 & -0.0468 & -0.0059 \\ \text { holding } & & & & & & \\ & -0.0591 & -0.0661 & -0.0579 & -0.0718 & -0.065 & -0.07 \\ \text { Pucca } & -0.1714 * & -0.1861 * & -0.1127 & -0.0957 & -0.1703 & -0.1459 \\ & -0.1032 & -0.1127 & -0.1043 & -0.1259 & -0.1127 & -0.1225 \\ \text { Muslim } & -0.1849 & -0.2029 & -0.055 & -0.0717 & -0.1532 * * & -0.0516 \\ & * * * & * * * & & & & -0.0698 \\ \text { Rural } & -0.0579 & -0.0653 & -0.0567 & -0.0715 & -0.0641 & 0.0842 \\ & 0.0692 & 0.0611 & 0.1028 & 0.1122 & 0.0585 & -0.0986\end{array}$


$\ln -\mathrm{L}$

$\begin{array}{llllll}-1236.31 & -1234.46 & -1252.36 & -1244.42 & -20929.25 & 21033.89\end{array}$

Note: Standard errors are shown below. Levels of significance: $*_{-} 10 \% ; *_{-} 5 \% ; *_{-} *_{-} 1 \%$ 
Table A2.3. Fixed effects logit estimates of mortality

$\begin{array}{lllllll}\text { Variable } & \begin{array}{l}\text { Male } \\ \text { Coefficient }\end{array} & \text { Se } & \text { T-stat } & \begin{array}{l}\text { Female } \\ \text { Coefficient }\end{array} & \text { Se } & \text { T-stat } \\ \text { Twin } & 2.4518 & 0.6556 & 3.74 & 2.7087 & 0.8660 & 3.128 \\ \text { Prior spacing } & -0.0821 & 0.0114 & -7.205 & -0.0473 & 0.01 & -4.733 \\ \text { Posterior Spacing } & -0.0478 & 0.00847 & -5.639 & -0.0383 & 0.0082 & -4.659 \\ & & & & & & \\ \text { Log-L } & -989.4407 & & & -989.004 & & \\ \text { Indiv. (hhs.) } & 6583 & & & 6319 & & \\ & (3126) & & & (2999) & & \end{array}$




\section{Appendix 3. Full Results for Tables 3}

Table 3.1B. Estimates of the Mortality Probit Equation

\begin{tabular}{|c|c|c|c|c|c|c|}
\hline & \multicolumn{4}{|c|}{ Uncorrelated estimates } & \multicolumn{2}{|c|}{ Correlated estimates } \\
\hline & \multicolumn{2}{|c|}{ Male } & \multicolumn{2}{|c|}{ Female } & Male & Female \\
\hline & No het & Het & No het & Het & With het & With het \\
\hline Intercept & -0.0291 & -0.0279 & $-0.2734 * *$ & $-0.3064 * *$ & 0.02 & $\begin{array}{c}-0.5666 \\
* * *\end{array}$ \\
\hline & 0.1143 & 0.1269 & 0.1106 & 0.1306 & 0.1911 & 0.1658 \\
\hline Mother literate & $-0.1685 * *$ & $-0.1773 * *$ & $-0.2283 * * *$ & $-0.2544 * * *$ & $-0.1674 * *$ & $\begin{array}{c}-0.2510 \\
* * *\end{array}$ \\
\hline & 0.067 & 0.0754 & 0.0634 & 0.0766 & 0.0762 & 0.0754 \\
\hline Twin & $\begin{array}{c}1.2387 * * * \\
0.1702\end{array}$ & $\begin{array}{c}1.2886 * * * \\
0.1901\end{array}$ & $\begin{array}{c}1.1822 * * * \\
0.154\end{array}$ & $\begin{array}{c}1.2583 * * * \\
0.1801\end{array}$ & $\begin{array}{c}1.2551 * * * \\
0.1969\end{array}$ & $\begin{array}{c}1.3386 \text { *** } \\
0.1822\end{array}$ \\
\hline First child is a female & $\begin{array}{c}-0.0940 * \\
0.0549\end{array}$ & $\begin{array}{l}-0.101 * \\
0.0608\end{array}$ & $\begin{array}{l}-0.033 \\
0.0539\end{array}$ & $\begin{array}{c}-0.0408 \\
0.0653\end{array}$ & $\begin{array}{c}-0.1013^{*} \\
0.054\end{array}$ & $\begin{array}{c}-0.0525 \\
0.0642\end{array}$ \\
\hline First child died & $\begin{array}{l}0.0853 \\
0.0593\end{array}$ & $\begin{array}{l}0.0961 \\
0.0683\end{array}$ & $\begin{array}{c}0.1446 * * \\
0.0604\end{array}$ & $\begin{array}{c}0.1608 * * \\
0.0741\end{array}$ & $\begin{array}{l}0.1066 \\
0.0695\end{array}$ & $\begin{array}{c}0.1714 * * \\
0.0728\end{array}$ \\
\hline Time since previous birth & $-0.0182 * * *$ & $-0.0193 * * *$ & $-0.0155 * * *$ & $-0.0165 * * *$ & $-0.0195 * * *$ & $\begin{array}{c}-0.0105 \\
* * *\end{array}$ \\
\hline Time to next birth & $\begin{array}{c}0.0021 \\
-0.0113 * * *\end{array}$ & $\begin{array}{c}0.0023 \\
-0.0118 * * *\end{array}$ & $\begin{array}{c}0.0021 \\
-0.0102 * * *\end{array}$ & $\begin{array}{c}0.0023 \\
-0.0110 * * *\end{array}$ & $\begin{array}{c}0.0034 \\
-0.0127 * * *\end{array}$ & $\begin{array}{c}0.0032 \\
-0.0077 \\
* * *\end{array}$ \\
\hline & 0.0017 & 0.0018 & 0.0014 & 0.0015 & 0.0025 & 0.0022 \\
\hline Agricultural land & $\begin{array}{c}-0.0281 \\
0.0576\end{array}$ & $\begin{array}{c}-0.0277 \\
0.066\end{array}$ & $\begin{array}{c}-0.0044 \\
0.0572\end{array}$ & $\begin{array}{l}0.0019 \\
0.0695\end{array}$ & $\begin{array}{c}-0.0288 \\
0.0668\end{array}$ & $\begin{array}{c}-0.0013 \\
0.0678\end{array}$ \\
\hline Pucca & $\begin{array}{c}-0.1735 * \\
0.1019\end{array}$ & $\begin{array}{c}-0.1846^{*} \\
0.1033\end{array}$ & $\begin{array}{l}-0.109 \\
0.1025\end{array}$ & $\begin{array}{l}-0.105 \\
0.1213\end{array}$ & $\begin{array}{c}-0.1954 * \\
0.1164\end{array}$ & $\begin{array}{c}-0.1445 \\
0.1185\end{array}$ \\
\hline Muslim & $\begin{array}{c}-0.2026 * * * \\
0.057\end{array}$ & $\begin{array}{c}-0.2212 * * * \\
0.0659\end{array}$ & $\begin{array}{l}-0.0285 \\
0.0571\end{array}$ & $\begin{array}{l}-0.036 \\
0.0696\end{array}$ & $\begin{array}{c}-0.2082 * * * \\
0.0676\end{array}$ & $\begin{array}{l}-0.0099 \\
0.0684\end{array}$ \\
\hline Rural & $\begin{array}{l}0.0532 \\
0.0843\end{array}$ & $\begin{array}{l}0.0395 \\
0.0941\end{array}$ & $\begin{array}{l}0.0812 \\
0.0819\end{array}$ & $\begin{array}{c}0.085 \\
0.0984\end{array}$ & $\begin{array}{l}0.038 \\
0.095\end{array}$ & $\begin{array}{l}0.0717 \\
0.0966\end{array}$ \\
\hline
\end{tabular}


Table 3.1C. Correlated and uncorrelated estimates of prior and posterior spacing, Male

\begin{tabular}{|c|c|c|c|c|c|c|}
\hline & \multicolumn{4}{|c|}{ Uncorrelated estimates } & \multicolumn{2}{|c|}{ Correlated estimates } \\
\hline & \multirow{2}{*}{\multicolumn{2}{|c|}{$\begin{array}{c}\text { Spacing } \\
\text { Posterior }(N E X T)\end{array}$}} & \multirow{2}{*}{\multicolumn{2}{|c|}{$\begin{array}{c}\text { Spacing } \\
\text { Prior }(P R E V)\end{array}$}} & \multirow{3}{*}{$\begin{array}{l}\text { Posterior } \\
(N E X T) \\
\text { With het }\end{array}$} & \multirow{3}{*}{$\begin{array}{c}\text { Prior } \\
(P R E V) \\
\text { With het }\end{array}$} \\
\hline & & & & & & \\
\hline & No het & With het & No het & With het & & \\
\hline \multirow[t]{2}{*}{$0-12$ months } & $0.6815 * * *$ & $0.6720 * * *$ & $0.6794 * * *$ & $0.6924 * * *$ & $0.6817 * * *$ & $0.6701 * * *$ \\
\hline & 0.0955 & 0.0956 & 0.0854 & 0.086 & 0.1069 & 0.0936 \\
\hline \multirow[t]{2}{*}{ 12-24 months } & $0.1494 * * *$ & $0.1535 * * *$ & $0.1263 * * *$ & $0.1480 * * *$ & $0.1587 * * *$ & $0.1445 * * *$ \\
\hline & 0.0063 & 0.0066 & 0.0057 & 0.0061 & 0.0076 & 0.0068 \\
\hline \multirow[t]{2}{*}{$>24$ months } & -0.0012 & 0.0022 & $-0.0033 * *$ & $0.0137 * * *$ & $0.0070 * * *$ & $0.0114 * * *$ \\
\hline & 0.0011 & 0.0019 & 0.0014 & 0.0018 & 0.0018 & 0.0021 \\
\hline \multirow[t]{2}{*}{ Intercept } & $-12.1042 * * *$ & $-12.0419 * * *$ & $-12.3027 * * *$ & $-12.7032 * * *$ & $\begin{array}{c}-12.6949 \\
* * *\end{array}$ & $-12.4216 * * *$ \\
\hline & 1.1193 & 1.1212 & 1.0009 & 1.0155 & 1.2682 & 1.1066 \\
\hline \multirow[t]{2}{*}{ Previous delivery problems } & -0.1355 & -0.1443 & 0.1 & 0.1254 & -0.1021 & 0.0748 \\
\hline & 0.0875 & 0.0956 & 0.0859 & 0.1363 & 0.1219 & 0.1275 \\
\hline \multirow[t]{2}{*}{ Age at first birth } & $-0.0139 * *$ & $-0.0148 * *$ & -0.003 & 0.0003 & $-0.0153 *$ & 0.0006 \\
\hline & 0.0068 & 0.0075 & 0.0057 & 0.0089 & 0.0089 & 0.0087 \\
\hline \multirow[t]{2}{*}{ Mother literate } & $-0.0877 * *$ & $-0.0931 *$ & $0.0694 *$ & 0.0936 & $-0.083 *$ & $0.0683^{*}$ \\
\hline & 0.0445 & 0.0496 & 0.0409 & 0.0644 & 0.0417 & 0.04039 \\
\hline \multirow[t]{2}{*}{ Twin } & 0.0685 & 0.0804 & & & 0.0166 & \\
\hline & 0.1507 & 0.1631 & & & 0.194 & \\
\hline \multirow[t]{2}{*}{ First child is female } & $0.0731 * *$ & $0.0796 *$ & 0.0384 & 0.042 & $0.0950 * *$ & 0.0309 \\
\hline & 0.0359 & 0.0409 & 0.0337 & 0.0525 & 0.0484 & 0.0511 \\
\hline \multirow[t]{2}{*}{ First child died } & 0.0056 & 0.0093 & $0.1153 * * *$ & $0.1654 * * *$ & 0.0356 & $0.1535 * * *$ \\
\hline & 0.0419 & 0.0476 & 0.0369 & 0.0581 & 0.0569 & 0.0567 \\
\hline \multirow[t]{2}{*}{ Time since previous birth } & $-0.0119 * * *$ & $-0.0116 * * *$ & & & $-0.0038 *$ & \\
\hline & 0.0014 & 0.0014 & & & 0.002 & \\
\hline \multirow[t]{2}{*}{ Agricultural land } & 0.0035 & 0.0043 & 0.0248 & 0.0291 & 0.0277 & 0.0464 \\
\hline & 0.0381 & 0.0426 & 0.0354 & 0.0539 & 0.0514 & 0.0527 \\
\hline
\end{tabular}




\begin{tabular}{lcccccc} 
Pucca & $-0.1125 *$ & $-0.1217 *$ & $0.0966 *$ & 0.1174 & $-0.1237 *$ & $0.1276^{*}$ \\
& 0.0629 & 0.0708 & 0.0585 & 0.0915 & 0.0699 & 0.0686 \\
Radio & -0.0067 & -0.0059 & -0.0236 & -0.0294 & 0.0161 & 0.0083 \\
& 0.042 & 0.0465 & 0.0362 & 0.0573 & 0.0551 & 0.0552 \\
Television & -0.0542 & -0.0429 & 0.0235 & 0.0057 & -0.0315 & -0.0404 \\
\multirow{2}{*}{ Muslim } & 0.0693 & 0.0781 & 0.0734 & 0.1147 & 0.0979 & 0.112 \\
\multirow{2}{*}{ Rural } & 0.0446 & 0.0442 & 0.0478 & 0.0668 & 0.0534 & 0.0416 \\
& 0.0374 & 0.042 & 0.0336 & 0.0548 & 0.051 & 0.0534 \\
& 0.0349 & 0.0334 & 0.0221 & -0.1122 & -0.0244 & -0.0934 \\
Ln-L & 0.0532 & 0.0595 & 0.0492 & 0.0779 & 0.0722 & 0.0764 \\
& & & & & & \\
& -9998.88 & -9996.85 & -9792.72 & -9745.76 & -20901.5 & -20901.52
\end{tabular}

Note: Standard errors are shown below. Levels of significance: $*_{-} 10 \% ; *_{-} 5 \% ; * *_{-} 1 \%$ 
Table 3.1D. Correlated and uncorrelated estimates of prior and posterior spacing, Female

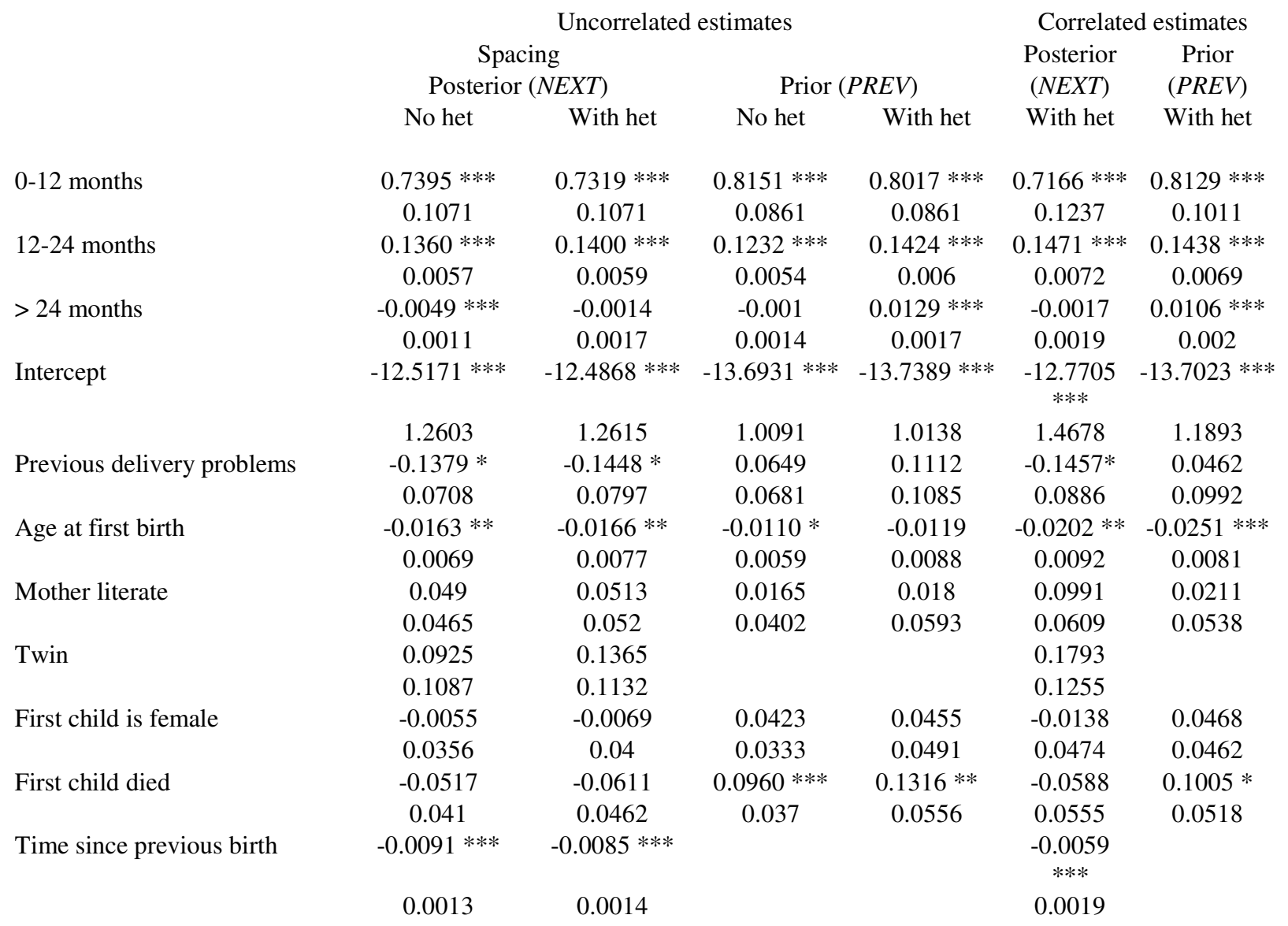




\begin{tabular}{lcccccc} 
Agricultural land & 0.0072 & 0.0047 & 0.0086 & 0.0045 & -0.0317 & -0.0295 \\
Pucca & -0.0383 & -0.0432 & -0.036 & -0.0539 & -0.0516 & -0.0499 \\
& -0.0815 & -0.0857 & -0.0228 & -0.0179 & -0.0951 & -0.0558 \\
Radio & -0.0692 & -0.0756 & -0.0583 & -0.0847 & -0.0894 & -0.0778 \\
& -0.064 & -0.07 & -0.0334 & -0.0409 & -0.0765 & 0.0062 \\
Television & -0.0415 & -0.0462 & -0.0365 & -0.0539 & -0.0538 & -0.0505 \\
\multirow{2}{*}{ Muslim } & -0.0898 & -0.0924 & -0.0016 & 0.0056 & -0.0746 & 0.0081 \\
& -0.0816 & -0.0896 & -0.0776 & -0.1094 & -0.1035 & -0.1011 \\
Rural & 0.043 & 0.0537 & $0.0795 * *$ & 0.0847 & 0.0362 & $0.0828 *$ \\
& -0.0374 & -0.0421 & -0.0344 & -0.0519 & -0.0504 & -0.0481 \\
& -0.0606 & -0.0654 & -0.0812 & -0.0828 & -0.028 & -0.0152 \\
ln-L & -0.0551 & -0.0609 & -0.0506 & -0.0734 & -0.0721 & -0.0695
\end{tabular}

Note: Standard errors are shown below. Levels of significance: $*_{-} 10 \%$; **-5\%; ***-1\% 


\section{NOTES}

${ }^{\mathrm{i}}$ Several plausible factors were highlighted for the unexpected underestimation of the negative effects of fertility on child mortality, including the experimental design of the data from Matlab project and relatively short period of the study.

ii Although there are younger women in our sample who have not completed fertility, our estimates seem to be robust. Not only we include mother's age at birth as a control variable in the spacing equation, but also our analysis focuses on middle-order children born to these women. In particular, we use hazard equations to determine prior and posterior spacing; oldest children are censored in the prior spacing equation while youngest ones are censored in the posterior spacing equation.

${ }^{\text {iii }}$ Rosenzweig (1986) noted the problem of estimating the health production function, given that spacing could be correlated with child specific unobserved characteristics. Accordingly, he compared OLS estimates with fixed effects (FFE) and lagged instrumental variable fixed effects (LIFE). These results, as summarised in Table 3 of his paper (p. 69), suggest that there is big difference between OLS and the other methods. FFE and LIFE estimates are qualitatively similar although there is some evidence that the FFE may under-estimate the effect of spacing. Unfortunately we do not have any suitable instrumental variables including the kind used by Rosenzweig. We note however that our correlated estimates are similar to the fixed effects estimates suggesting that the birth spacing effect is robust.

${ }^{\text {iv }}$ Wolpin (1984) develops a finite-horizon dynamic stochastic model of discrete choice with respect to life-cycle fertility in a world where infant survival is uncertain and offers results for the number, timing and spacing of children for exogenous child mortality. We however choose to focus on Rosenzweig (1986) because of its direct relevance for our purpose.

${ }^{\mathrm{v}}$ In other estimations, posterior spacing with respect to other subsequent siblings was never significant and we do not therefore consider it in this analysis. (See also Makepeace and Pal, 2006).

vi This works in conjunction with other possible factors, for example, cultural preference for sons in certain societies or the biological factors (e.g., maternal depletion due to shorter birth interval). See further discussion later in the section.

vii The number of sisters (or brothers) depends on the choice of family size and is therefore endogenous. Larger families tend to have more girls because fertility is endogenous with respect to child's sexfamilies who have a target number of boys continue to have more children if they have girls early on, but stop if they have boys. Thus the probability of having a sister increases with the number of siblings. However, the gender of the first child cannot be correlated with the gender and other aspects of the second child although it is correlated with number of children of a particular gender and can therefore be used as an instrument.

viii Infant mortality rate in 1992 was 79 in India as against 18 in Sri Lanka, 31 in China, 13 in South Korea and 26 in Thailand per 1000 live births in the year.

${ }^{\text {ix }}$ Number of infants dying before reaching one year of age is expressed per 1000 live births in a year.

${ }^{x}$ The second NFHS undertaken in 1998-99 was designed to strengthen the database further and facilitate implementation and monitoring of population and health programmes in the country. Though some additional information (e.g., height and weight of all eligible women, blood test for women and children) were collected, the information that we use remained very similar. Our preliminary analysis also yielded similar results as reported here.

${ }^{x i}$ We have also tried to include all children in our estimation. In this case, prior spacing for oldest child was estimated by the time between mother's age at marriage and birth of the first child while posterior spacing for the youngest child was the time elapsed between the birth of the child and the time of the survey (for non-sterilised couple) or the time the couple was sterilised. However the log-likelihood function would not converge probably because of the poor quality of the available information (age at marriage, number of marriages or time of sterilisation), which in turn resulted in rather sporadic distribution of prior/posterior spacing of the oldest/youngest children in our sample. Note that the estimation of prior and posterior spacing hazard equations indirectly takes account of first born and youngest children as censoring variables.

xii A short note on this is available from the authors on request. 
xiii In an alternative specification, we also estimate a mortality hazard equation to compare with the mortality probit estimates. These hazard estimates are shown in Appendix 2 Table A2.1.

${ }^{\text {xiv }}$ One, however, needs to be careful about the treatment of the twins and the corresponding birth order since birth order in our data-set is recorded in a continuous fashion, without taking account of the twin birth. Here, we have given the second born twin the same birth order as the first born.

${ }^{\mathrm{xv}}$ We however cannot analyse the effects of specific health inputs (e.g., prenatal care, hospital delivery or child vaccination) on child mortality (e.g., Maitra 2004) since these information were only collected for children born in the last 3 years (this holds for both rounds of NFHS).

xvi Information about the father was collected from the woman concerned. First, there were lots of missing as well as inconsistent values for father's age. Second, most fathers were literate, which was in turn causing problems of convergence when included. Hence, we could not include comparable characteristics of the father as we did for the mother.

${ }^{\text {xvii }}$ Most households in our sample are Hindus or Muslims. Only a minority of households belong to other religions. When we modelled these differences, only the Muslim dummy was robust and consistently significant.

xviii The observations are grouped by mother so the factor is strictly speaking mother-specific. However, family break-ups are extremely rare so we interpret this more broadly as a family-specific effect.

${ }^{\text {xix }}$ While we could treat mother's age at first birth as an exogenous variable (evidence suggests that use of contraception is almost non-existent before the birth of the first child), we could not ignore the element of simultaneity in mother's age at birth of each child.

${ }^{x x}$ Analysis of NFHS 92-93 data (see Table 1B) suggests that compared to Hindus, a significantly larger proportion of Muslim couples use no contraception. In particular, compared to Muslim couples, more than double of the Hindu couples are sterilised while use of modern (use of pills, IUD/copper, injections and condoms) or traditional (abstinence/withdrawal) non-terminal methods of contraception is rather comparable among these two religious groups in our sample.

${ }^{x x i}$ In order to check the robustness of our correlated estimates, we have also re-estimated the correlated model, after dropping the household-specific variables in case there is a correlation between householdspecific observable variables with the unobserved heterogeneity terms. The estimates are rather similar to the ones presented in Table 4B. So we do not present these estimates. 